\title{
A Rare Sternal Lesion on Magnetic Resonance Mammography Mimicking a Metastasis in a Patient With a History of Mamma Carcinoma: A Case Report
}

\author{
Karin Zuidberg-van der Gronde ${ }^{\mathrm{a}, \mathrm{c}}$, Caroline Klazen ${ }^{\mathrm{a}}$, Joop van Baarlen ${ }^{\mathrm{b}}$, \\ Roland Bezooijen ${ }^{\mathrm{a}}$
}

\begin{abstract}
A 48-year-old female patient was sent to the radiology department for her annual control magnetic resonance imaging (MRI) after mastectomy for breast cancer. The MRI showed a solitary lesion in the manubrium sterni with homogeneous enhancement. Computed tomography (CT) showed a sclerotic lesion. The lesion showed minimal activity on bone scintigraphy. A biopsy was performed and histology revealed a lesion consisting of brown fat. The lesion was diagnosed as an intraosseous hibernoma. This case report highlights the importance of histologic confirmation of a suspected metastasis, since rare lesions can mimic metastases on imaging.
\end{abstract}

Keywords: Intraosseous hibernoma; Benign lesion; Metastasis; Breast cancer; Sternal lesion; MR mammography; Histology

\section{Introduction}

We present a case of a woman (age 48) known with a history of breast carcinoma, in whom a sternal lesion was found on magnetic resonance imaging (MRI). In histology, this sternal lesion turned out to be an intraosseous hibernoma instead of a metastasis. Hibernomas are rare lipomatous lesions that exist of brown fat. Usually they arise in the subcutis or within skeletal muscle, rarely in bone $[1,2]$. In this case, it was found during the screening for recurrence or metastases, which made it suspicious. This case shows the importance of histologic confirmation of a suspected metastasis, since rare lesions can mimic metastases on imaging, as in this case an intraosseous hibernoma.

Manuscript accepted for publication April 05, 2017

${ }^{a}$ Department of Radiology, Medisch Spectrum Twente, Koningsplein 1, 7512 KZ Enschede, The Netherlands

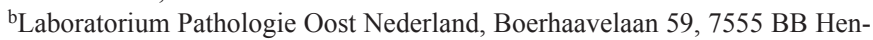
gelo, The Netherlands

${ }^{\mathrm{c}}$ Corresponding Author: Karin Zuidberg-van der Gronde, Bergpoortstraat 34, 7411 CM Deventer, The Netherlands. Email: kmvdg@hotmail.com

doi: https://doi.org/10.14740/jmc2803w

\section{Case Report}

A 48-year-old Caucasian female patient was sent to our department for her annual screening MRI of the left breast. Three years ago, she was diagnosed with a moderately differentiated infiltrating ductal carcinoma in the right breast and a mastectomy of the right breast was performed. No evidence of recurrent carcinoma or new carcinoma was seen on the screening MRI. However, the MRI showed an oval solitary lesion with a diameter of $1.4 \mathrm{~cm}$ central in the manubrium sterni. On the T2weighted images, the lesion has a hyperintense rim and central inhomogeneous signal intensity (Fig. 1a). On the T1 fat-sat, the lesion is isointense with a slightly hyperintense rim (Fig. 1b). After admission of gadolinium, the lesion enhanced homogeneously without wash-out (Fig. 1c). In retrospective, the lesion was visible on MRI 2 years before and did not change. This did not exclude a metastasis, since patient was treated with chemotherapy.

Metastasis had to be considered and was most likely. However, the whole-body bone scintigraphy with tomography was not suspicious for bone metastases. Computed tomography (CT) evaluation on the site of the intraosseous lesion revealed an irregular and poorly defined sclerotic lesion, unchanged compared to 1.5 years before on the CT. Both CT scans were made in combination with bone scintigraphy. Only a closer look on the bone scintigraphy revealed minimal activity in the right side of the manubrium sterni with slight sclerosis, vaguely demarked, with a diameter of $1 \mathrm{~cm}$ (Fig. 2).

Despite negative bone scintigraphy, bone metastasis could not be excluded and was still in the differential diagnosis. Therefore, a CT-guided biopsy was performed with a $13 \mathrm{G}$ bone needle $\left(\mathrm{Cook}^{\circledR}\right)$. This was achieved without complications.

On microscopy, the biopsy showed lamellar bone marrow with traces of hematopoietic tissue. Some cells are present with numerous fine vacuolated cytoplasm and a centrally located small nucleus (Fig. 3a).

No carcinoma cells were seen, not even with AE1/AE3, CAM5.2 immunohistochemistry. CD68 showed many macrophages, but the multivacuolated cells remained negative. These cells were positive for S-100 (Fig. 3b). These morphological and immunohistochemical characteristics of the tissue exclude malignancy and correspond to brown fat. Combined with the T2 and MRI characteristics, the lesion was diagnosed 

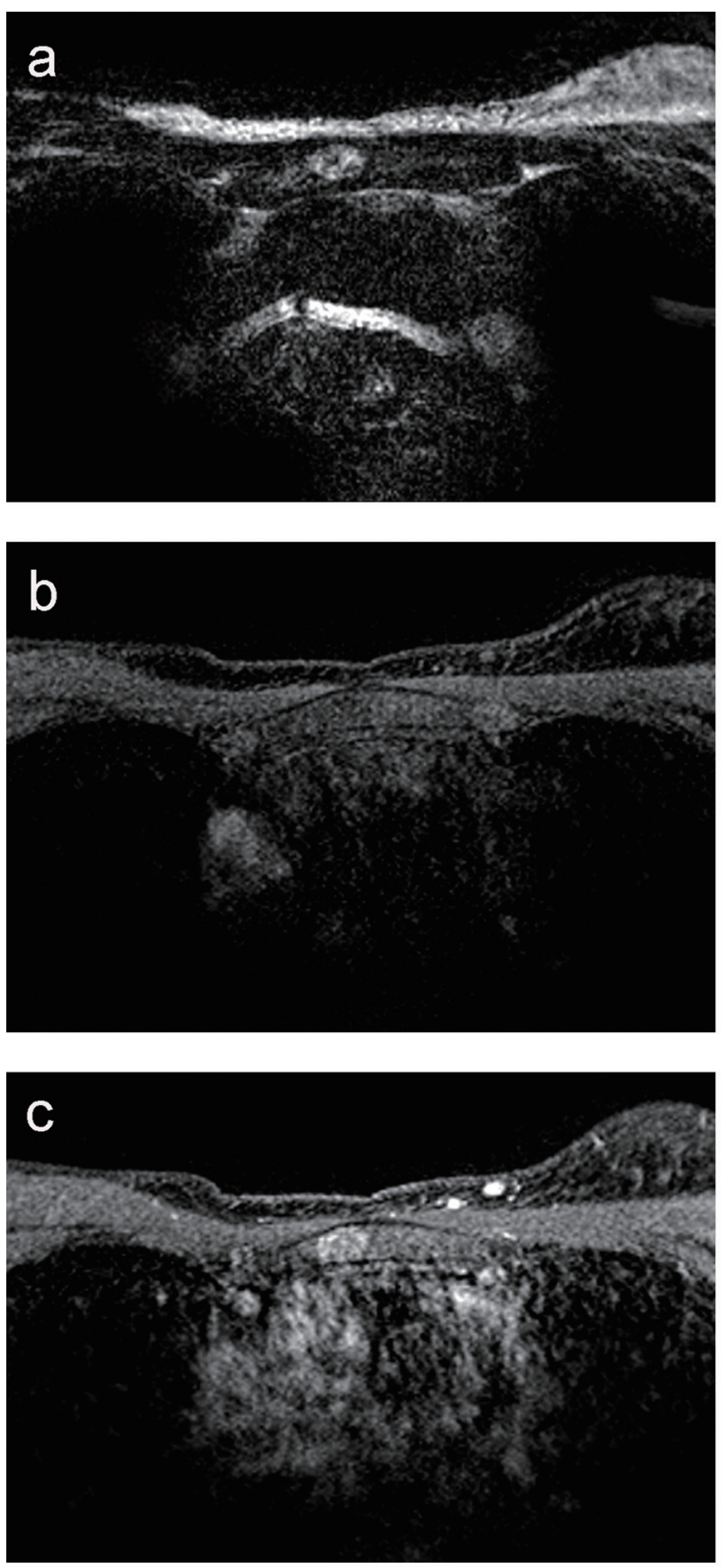

Figure 1. (a) MRI T2-weighted image of the manubrium sterni: the lesion has a hyperintense rim and central inhomogeneous signal intensity, and has a diameter of $1.4 \mathrm{~cm}$. (b) MRI T1 fat-sat: the lesion is isointense with a slightly hyperintense rim. (c) MRI T1 fat-sat after the admission of gadolinium: the lesion enhances homogeneously without wash-out.

an intraosseous hibernoma.

Following this finding, the patient was reassured that it was a benign tumor. She remained under control. A control MRI followed to check for relapse or new malignancy. The intraosseous hibernoma was also monitored this way. One year later, the intraosseous hibernoma was not changed.

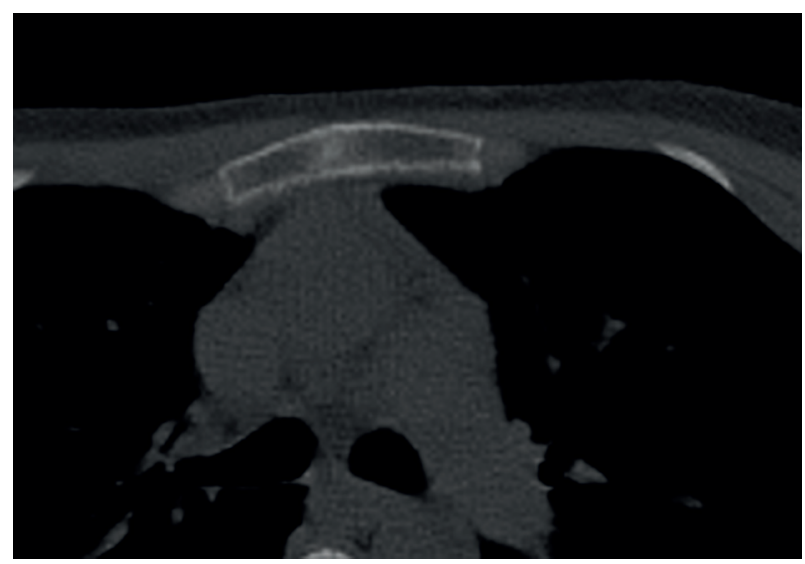

Figure 2. Image of the sternum on CT. A sclerotic lesion is shown, irregular and poorly defined.

\section{Discussion}

Benign lesions might mimic metastases. This is one of the reasons why it is important to obtain histology. In this case, the characteristics of the lesion on MRI and CT were similar to metastases. A biopsy was needed to make the diagnosis of a hibernoma, a benign lesion. By excluding a metastasis, the patient did not need (additional) chemotherapy or radiotherapy.

The hibernoma in this case is a rare benign lesion consisting of brown fat. It is called hibernoma because of its resemblance to the brown fat in hibernating animals [3]. They occur most commonly in soft tissue, usually in middle-aged and elderly individuals. An intraosseous hibernoma is very rare, and only 16 cases have been reported until now [4]. Until now, only one other intraosseous hibernoma in the manubrium sterni of a male has been documented. Other hibernomas occurred bilateral in the femur $(\times 1)$, ischiopubic ramus $(\times 1)$, spine $(\times$ $3)$, sacrum $(\times 5)$, and in the ilium $(\times 5)[1,2,5-7]$. All hibernomas have been found staging for malignancy or as incidental findings. Only in one case, the hibernoma was supposed to be symptomatic. In two other scans, made for pain evaluation, it was the only abnormal finding [5].

\section{Imaging characteristics of hibernomas}

The intraosseous hibernoma in our case was sclerotic and in contrary to other case reports poorly defined on CT. Some described intraosseous hibernomas have a lucency, and one was solitary described as a lucency on CT [1]. However, 11 of the 12 imaged on CT, are described as mainly sclerotic [2, 4-9]. The MRI characteristics are previously described as T1 hypointense to subcutaneous fat and hyperintense to muscle $[5,9]$ or isointense $[7,8]$. The STIR characteristics are only once described as hyperintense [8]. The intraosseous hibernoma in our case is isointense on T1 fat-sat sequences. After intravenous gadolinium admission, it showed enhancement, as mentioned in five cases of seven previous cases $[4,6,9]$. On bone scintigraphy, our case showed just minimal uptake, as mentioned in two other cases, whereas in three previously 

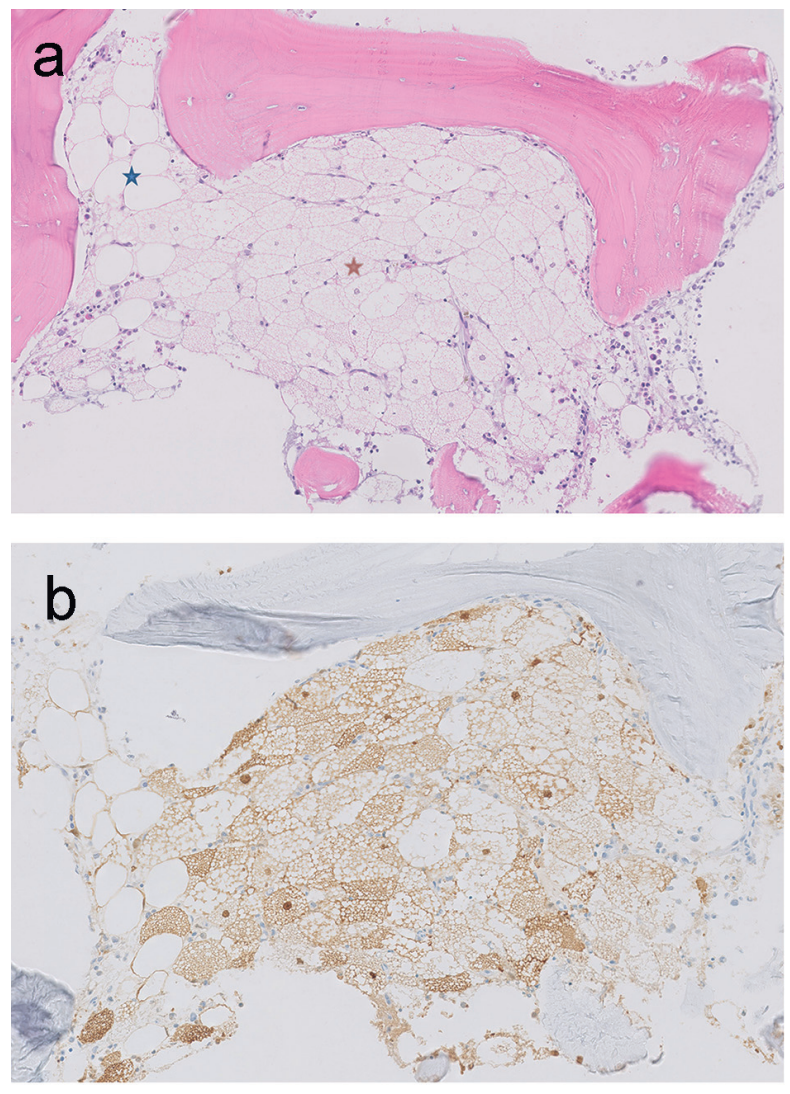

Figure 3. (a) Photomicrograph of the specimen (hematoxylin-eosin stain). The image shows areas of fat cells with multiple cytoplasmic vacuoles (red star), matching brown fat, positioned next to bone trabeculae. For comparison, also normal fat cells in the image (blue star). That it concerns fat cells is supported by positive immunohistochemical accentuation with S-100. (b) Photomicrograph of the specimen (S-100 stain), showing positive immunohistochemical accentuation.

described cases of intraosseous hibernomas, a pronounced uptake was shown $[1,5]$.

These imaging characteristics are also seen in metastases of breast carcinoma. The incidence of bone metastases is reported to be $6-6.5 \%[10,11]$. In sixty-nine percent of diagnosed bone metastases, the chest cage is one of the locations where metastases are found [12]. Since metastases have a much higher incidence, this is a more likely diagnosis. Only biopsy can distinguish between a metastasis and an intraosseous hibernoma.

\section{Histology hibernoma}

Most important in this case was to exclude a metastasis. Negative staining with AE1/AE3 and CAM5.2 immunohistochemistry did exclude a metastasis. Immunohistochemical staining with S-100 was positive, characteristic of fat cells. Within the fat cells multiple cytoplasmic vacuoles were seen, matching brown fat. This matches previous descriptions of intraosseous hibernomas $[1,4,5,8,9]$. Unlike hibernomas in soft tissue, intraosseous hibernomas do not show marked hyper vascularity of the tissue $[3,13]$.

\section{Conclusion}

Intraosseous hibernomas are extremely rare. Therefore, it is not logical to include intraosseous hibernomas in the differential diagnosis of bone lesions in a patient with breast cancer. However, this case does show the importance of histology to exclude malignancy in a suspected metastasis, since rare benign lesions, such as the described intraosseous hibernoma, can mimic metastases on imaging. For this reason, we want to address the importance of histology to exclude benign lesions in general.

\section{Grant}

This research did not receive any specific grant from funding agencies in the public, commercial, or not-for-profit sectors.

\section{Conflicts of Interest}

None.

\section{References}

1. Westacott L, Collins A, Dickenson I. Intraosseous Hibernoma in the Sacrum of an Adult. Int J Surg Pathol. 2016;24(8):749-752.

2. Hafeez I, Shankman S, Michnovicz J, Vigorita VJ. Intraosseous hibernoma: a case report and review of the literature. Spine (Phila Pa 1976). 2015;40(9):E558-561.

3. Murphey MD, Carroll JF, Flemming DJ, Pope TL, Gannon FH, Kransdorf MJ. From the archives of the AFIP: benign musculoskeletal lipomatous lesions. Radiographics. 2004;24(5):1433-1466.

4. Bai S, Mies C, Stephenson J, Zhang PJ. Intraosseous hibernoma: a potential mimic of metastatic carcinoma. Ann Diagn Pathol. 2013;17(2):204-206.

5. Bonar SF, Watson G, Gragnaniello C, Seex K, Magnussen J, Earwaker J. Intraosseous hibernoma: characterization of five cases and literature review. Skeletal Radiol. 2014;43(7):939-946.

6. Ringe KI, Rosenthal H, Langer F, Callies T, Wacker F, Raatschen HJ. Radiofrequency ablation of a rare case of an intraosseous hibernoma causing therapy-refractory pain. J Vasc Interv Radiol. 2013;24(11):1754-1756.

7. Vlychou M, Teh J, Whitwell D, Athanasou NA. Intraosseous hibernoma: a rare adipocytic bone tumour. Skeletal Radiol. 2016;45(11):1565-1569.

8. Botchu R, Puls F, Hock YL, Davies AM, Wafa H, Grimer RJ, Brocker V, et al. Intraosseous hibernoma: a case report and review of the literature. Skeletal Radiol. 2013;42(7):1003-1005.

9. Kumar R, Deaver MT, Czerniak BA, Madewell JE. Intraosseous hibernoma. Skeletal Radiol. 2011;40(5):641-645.

10. Hagberg KW, Taylor A, Hernandez RK, Jick S. Incidence of bone metastases in breast cancer patients in the United 
Kingdom: results of a multi-database linkage study using the general practice research database. Cancer Epidemiol. 2013;37(3):240-246.

11. Liede A, Jerzak KJ, Hernandez RK, Wade SW, Sun P, Narod SA. The incidence of bone metastasis after earlystage breast cancer in Canada. Breast Cancer Res Treat. 2016;156(3):587-595.
12. Kuchuk I, Hutton B, Moretto P, Ng T, Addison CL, Clemons $\mathrm{M}$. Incidence, consequences and treatment of bone metastases in breast cancer patients-Experience from a single cancer centre. J Bone Oncol. 2013;2(4):137-144.

13. Dursun M, Agayev A, Bakir B, Ozger H, Eralp L, Sirvanci $M$, Guven K, et al. CT and MR characteristics of hibernoma: six cases. Clin Imaging. 2008;32(1):42-47. 